\title{
Carbon dioxide adsorption on zeolites and activated carbon by pressure swing adsorption in a fixed bed
}

\author{
Lalhmingsanga Hauchhum • Pinakeswar Mahanta
}

Received: 12 February 2014/ Accepted: 10 June 2014/Published online: 2 August 2014

(C) The Author(s) 2014. This article is published with open access at Springerlink.com

\begin{abstract}
Combustion of fossil fuels is one of the major sources of greenhouse gas (GHG) $\mathrm{CO}_{2}$, it is therefore necessary to develop technologies that will allow us to utilize the fossil fuels while reducing the emissions of GHG. Removal of $\mathrm{CO}_{2}$ from flue gasses has become an effective way to mitigate the GHG and adsorption is considered to be one of the methods. Adsorption of $\mathrm{CO}_{2}$ on zeolite $13 \mathrm{X}$, zeolite $4 \mathrm{~A}$ and activated carbon (AC) have been investigated at a temperature ranging from 25 to $60{ }^{\circ} \mathrm{C}$ and pressure up to 1 bar. The experimental data were fitted with isotherm models like Langmuir and Freunlich isotherm model. The Langmuir model fit well with the two zeolites and Freunlich model fit well with AC. The thermodynamics parameters were calculated and found to be exothermic in natures for all three adsorbents. Moreover, regeneration studies have been conducted in order to verify the possibility of activated carbon reutilization, to determine its $\mathrm{CO}_{2}$ adsorption capacity within consecutive cycles of adsorption-desorption. Temperature swing adsorption was employed as the regeneration method through heating up to a temperature of approximately $100{ }^{\circ} \mathrm{C}$. There is no full reversibility for zeolites while $\mathrm{AC}$ can achieve complete regenerations.
\end{abstract}

Keywords Adsorption - Carbon dioxide .

Thermodynamic parameters $\cdot$ Activated carbon $\cdot$ Zeolite

L. Hauchhum $(\bowtie) \cdot$ P. Mahanta

Department of Mechanical Engineering, Indian Institute

of Technology Guwahati, Guwahati 781039,

Assam, India

e-mail: h.sanga@iitg.ernet.in

P. Mahanta

e-mail: pinak@iitg.ernet.in

\section{Introduction}

The emission of gaseous products of combustion into the atmosphere, mainly Carbon dioxide $\left(\mathrm{CO}_{2}\right)$ is regarded as a major cause of global warming and climate change, through the so-called greenhouse effect [1]. Currently, $85 \%$ of total world demanded energy is supplied by thermal power plants fed by fossil fuels, including coal, oil and gas. They account for about $40 \%$ of total $\mathrm{CO}_{2}$ emissions [2]; Yang et al. [3]; [4]. Among the ways to control, reduce or mitigate this effect, the capture of $\mathrm{CO}_{2}$ from flue gasses of industrial combustion processes and its storage in deep geological formations is now being considered as a serious option [5-7].

A number of adsorption processes are used commercially for adsorbent process, including pressure swing adsorption (PSA), vacuum pressure swing adsorption (VPSA), and thermal or temperature swing adsorption (TSA). A number of research works have been done using the processes mentioned above on different types of adsorbent materials. Recent developments have demonstrated that PSA is a promising option for separating $\mathrm{CO}_{2}$ due to its ease of applicability over a relatively wide range of temperature and pressure conditions, its low energy requirements, and its low capital investment cost (Agarwal et al. [8]). Many studies concerning $\mathrm{CO}_{2}$ removal from various flue gas mixtures by means of PSA processes have been addressed in the literature. Prior to the design of an adsorption process, selecting an appropriate adsorbent with high selectivity and working capacity, as well as a strong desorption capability, is key to separating $\mathrm{CO}_{2}$. As a result, a wide variety of adsorbents like activated carbon, zeolites, silica gel, activated alumina, urea-formaldehyde and melamine-formaldehyde resins, poly-ethyleneimine and hollow fiber carbon membranes based adsorbents, etc. have 
been investigated for this purpose [9]; Sircar et al. [10]; $[11,12,17]$. Recent development shows an improvement in adsorbent materials with higher adsorption capacity and selectivity like Activated carbon honeycomb monolithZeolite 13X hybrid system, zeolites NaKA and nanoNaKA, FAU zeolites and zeolite 13X prepared from bentonite [13-16].

The PSA process is based on preferential adsorption of the desired gas on a porous adsorbent at high pressure, and recovery of the gas at low pressure. Thus, the porous sorbent can be reused for subsequent adsorption. PSA technology has gained interest because of the low energy requirements and low capital investment costs. The low recovery rate of $\mathrm{CO}_{2}$ is one of the problems reported with the PSA process [18]. Development of regenerable sorbents that have high selectivity, adsorption capacity, and adsorption/desorption rates for $\mathrm{CO}_{2}$ capture is critical for the success of the PSA process. Cost of the sorbent is also a major factor that needs to be considered for the process to be economical $[19,20]$.

The adsorption method of choice for many zeolite molecular sieves is PSA, although some experiments have employed a combined pressure and temperature swing adsorption (PTSA) process (Ruthven et al. [21]; $[22,23]$. It has been reported that a particular TSA and PSA cycle conditions would result in higher expected working capacity with an increase in feed temperature. Zeolites have shown promising results for the separation of $\mathrm{CO}_{2}$ from gas mixtures and can potentially be used for the PSA process. Natural zeolites are inexpensive and can be viable sorbents if they work for the process application [24]. It has also been reported that using AC as an adsorbent material, the adsorption capacity can increase till 30 Bar and become steady after 30-35 bars [25].

Based on the literatures available, PSA seems to be the best option for separating $\mathrm{CO}_{2}$ from flue gas due to its ease of applicability over a relatively wide range of temperature and pressure conditions. A number of sorbents like zeolite, activated alumina, activated carbons, etc. have been utilized and cost of the sorbents play a vital role for the process to be economical. In this paper, low cost and abundantly available locally, coconut fiber based AC was employed as the sorbent materials and compared with commercial zeolites. Work had been done to develop a process in which $\mathrm{CO}_{2}$ was adsorbed from a gas stream containing $\sim 13.8$ vol. $\%$ of $\mathrm{CO}_{2}$ onto zeolite $13 \mathrm{X}$, zeolite $4 \mathrm{~A}$ and $\mathrm{AC}$ by means of PSA process. The system was tested for five different adsorption and desorption cycles in order to determine the adsorbent bed's regeneration efficiencies. Kinetics and adsorption thermodynamics parameters have also been calculated.

\section{Materials and methods}

Materials

The properties of commercial zeolite $13 \mathrm{X}$ and Zeolite $4 \mathrm{~A}$ which were purchased from the local chemist are given in Table 1. While the AC (coconut fiber) used was obtained from a local area. It was peeled and the fibrous part was collected and was broken into small pieces. The coconut fibre was washed with water, dried in the sun for $10 \mathrm{~h}$ and transferred to the furnace. The coconut pieces were burnt distinctively in the furnace for an hour at a temperature of $350{ }^{\circ} \mathrm{C}$. The charcoal produced was withdrawn from the furnace and sieved; a mean particle diameter of $0.92 \mathrm{~mm}$ was obtained. The material characterization was done for proximate and ultimate analysis and details of the physical and chemical properties are given in Table 2.

Table 1 Properties of zeolites

\begin{tabular}{lll}
\hline Properties & $4 \mathrm{~A}$ & $13 \mathrm{X}$ \\
\hline BET surface area $\left(\mathrm{m}^{2} / \mathrm{g}\right)$ & 434 & 720 \\
Pore diameter $(\AA)$ & 4.0 & 10.0 \\
Bulk density $\left(\mathrm{kg} / \mathrm{m}^{3}\right)$ & 700 & 639 \\
Particles diameter $(\mathrm{mm})$ & 1.5 & 2 \\
Composition (wt \%) & & \\
Sodium & 10.8 & 11.9 \\
Aluminum & 13.6 & 14.3 \\
Silicon & 16.1 & 17.8 \\
Calcium & 0.8 & 0.6 \\
Potassium & 0.9 & 0.2 \\
Magnesium & 1.2 & 1.3 \\
\hline
\end{tabular}

Table 2 Properties of activated carbon

\begin{tabular}{|c|c|c|c|}
\hline \multicolumn{3}{|c|}{ BET surface area $\left(\mathrm{m}^{2} / \mathrm{g}\right)$} & 214 \\
\hline \multicolumn{3}{|c|}{ Pore volume $(\mathrm{cc} / \mathrm{g})$} & 0.068 \\
\hline \multicolumn{3}{|c|}{ Bulk density $\left(\mathrm{kg} / \mathrm{m}^{3}\right)$} & 350 \\
\hline \multicolumn{3}{|c|}{ Particles diameter (mm) } & 0.92 \\
\hline \multicolumn{4}{|c|}{ Ultimate analysis (wt \%) } \\
\hline $\mathrm{C}$ & $\mathrm{O}$ & $\mathrm{Cl}$ & $\mathrm{K}$ \\
\hline 41.28 & 36.00 & 6.01 & 33.71 \\
\hline \multicolumn{4}{|c|}{ Proximate analysis (wt \%) } \\
\hline Ash & Moisture & Fixed carbon & Volatile \\
\hline 4.8 & 10.63 & 14.49 & 70.08 \\
\hline
\end{tabular}




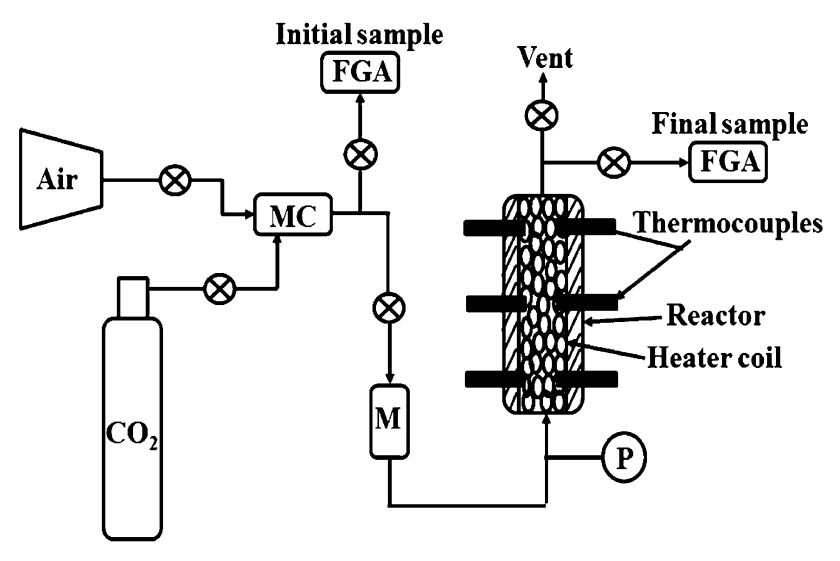

Fig. 1 Schematic of the experimental set-up for fixed bed. $M C$ mixing chamber, $M$ mass flow meter, $P$ pressure gage, $F G A$ flue gas analyzer

Table 3 Experimental conditions

\begin{tabular}{ll}
\hline Bed weight & $20 \mathrm{~g}$ \\
Reactor length & $200 \mathrm{~mm}$ \\
Reactor diameter & $30 \mathrm{~mm}$ \\
Influent $\mathrm{CO}_{2}$ concentration & $13.8 \mathrm{vol} . \%$ \\
Inlet flow rate & $15 \mathrm{LPM}$ \\
Bed porosity & 0.5 \\
Superficial velocity & $0.13 \mathrm{~m} / \mathrm{s}$ \\
Adsorption temperature & $25-60{ }^{\circ} \mathrm{C}$ \\
Adsorption total pressure & $1 \mathrm{bar}$ \\
\hline
\end{tabular}

\section{Methods}

The experimental set-up for the adsorption test consists of a $\mathrm{CO}_{2}$ cylinder and Gas Compressor interconnected through a pipe to the system as shown in Fig. 1 based on [25]. The Gas Compressor could provide sufficient pressure up to $10 \mathrm{~kg} / \mathrm{cm}^{2}$ with a discharge capacity of $84 \mathrm{LPM}$. The gas mixing chamber was made up of a GI pipe of $20 \mathrm{~mm}$ diameter and $80 \mathrm{~mm}$ in length to achieve the required mixture of air and $\mathrm{CO}_{2}(13.8$ vol. \%) at a constant rate. Ceramic wool was wrapped around the reactor above the heater coil for insulation. Thermocouples (K-type) were inserted in the bed to measure the bed temperatures with accuracy of $\pm 0.5 \%$.

A Glass Tube Rotameter of the range 0-35 LPM was used to control the mass flow rate and measure the mass flow rate of the incoming gas. The reactor was made up of GI pipe with $30 \mathrm{~mm}$ diameter with $1.5 \mathrm{~mm}$ wall thickness and $200 \mathrm{~mm}$ in height. A pressure monitoring system was attached to know the incoming pressure and experiments were carried at varying pressure to see the effect of pressure in the adsorption process at a constant temperature. A number of needle valves were attached in the system to control the system operation at the require rate. Flue Gas Analyzer (KM9106) was used to measure the inlet sample gas and the outlet gas properties. The apparatus was tested for leak absence and for accuracy through calibrations with an empty tank. Table 3 give details of the operating parameters.

The process employed a single-bed PSA unit. For the adsorption process, first the air was allowed to flow through the reactor and then followed by carbon dioxide. To maintain equal flow rate and pressure of both the flows, the gas mixture was allowed to pass through the mixing chamber. The flow of air was then stopped and allowed only the pure $\mathrm{CO}_{2}$ to flow through the reactor for measurement of the mass of $\mathrm{CO}_{2}$ adsorbed per the mass of the adsorbent. To know the effective adsorbed mass on the adsorbent materials, $Q_{\text {eff, }}$ two quantities were defined: $Q_{t}$ that is the mass containing the reactor including the adsorbents and $\mathrm{Q}_{\mathrm{d}}$ which is the mass of the empty reactor or dead volume. The $\mathrm{Q}_{\text {eff }}$ was then calculated with the equation as follows: $Q_{e f f}=Q_{t}-Q_{d}$.

\section{Results and discussions}

Adsorption breakthrough curves

Adsorption is a transient process and the amounts of material adsorbed within a bed depend both on position and time. The $\mathrm{CO}_{2}$ breakthrough curves for the three adsorbents are shown through Figs. 2, 3, 4 and the experimental conditions are given in Table 3. The breakthrough curves show ratio of the outlet concentration and the influent concentration against the contact time at an atmospheric pressure, and at a temperatures of $25,35,45$ and $60{ }^{\circ} \mathrm{C}$. The general pattern of the breakthrough curves were achieved as expected for all adsorbents. For zeolite 13X, the adsorption breakthrough occurs at $20 \mathrm{~min}$ and for zeolite $4 \mathrm{~A}$, the adsorption breakthrough occurs at $16 \mathrm{~min}$.

This shows that the pore diameter of zeolite $13 \mathrm{X}(10 \AA)$ and zeolite $4 \mathrm{~A}$ ( $4 \AA$ ) is sufficient for the $\mathrm{CO}_{2}$ to enter into the zeolites channels. The major cations of zeolites are $\mathrm{Na}$ and $\mathrm{K}$ and this major cation appears to play a main role in the adsorption of $\mathrm{CO}_{2}$. Also, sodium appears to be the favorable cation for the adsorption of $\mathrm{CO}_{2}$. The saturation time for zeolite $13 \mathrm{X}$ is longer than that of zeolite $4 \mathrm{~A}$ which is due to the larger pore volume. For AC, the breakthrough time is $8 \mathrm{~min}$ at $25^{\circ} \mathrm{C}$. The breakthrough time with $\mathrm{AC}$ was shorter as compared to zeolites, indicating that the $\mathrm{CO}_{2}$ adsorption capacity of AC is lower than that of zeolites. The differences in adsorption observed with zeolites and $\mathrm{AC}$ should be related to the differences in the chemical nature at the surface and porosity. Both the zeolites have higher surface area than $\mathrm{AC}$ and that may have contributed to the higher adsorption capacity of zeolites. 


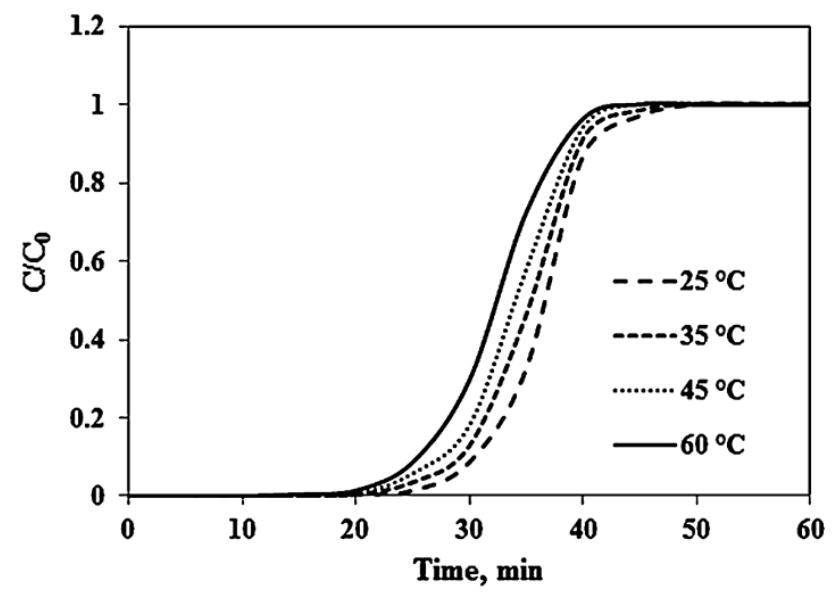

Fig. $2 \mathrm{CO}_{2}$ breakthrough curve for zeolite $13 \mathrm{X}$ at 1 bar

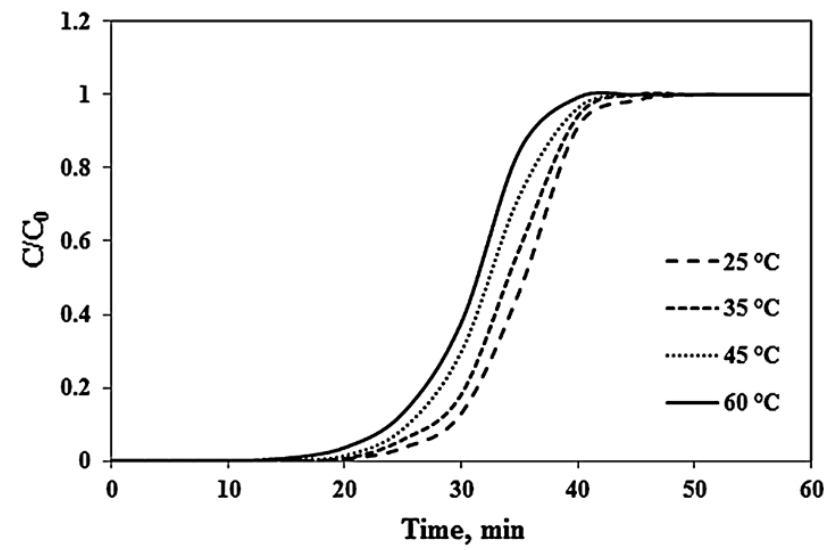

Fig. $3 \mathrm{CO}_{2}$ breakthrough curve for zeolite $4 \mathrm{~A}$ at 1 bar

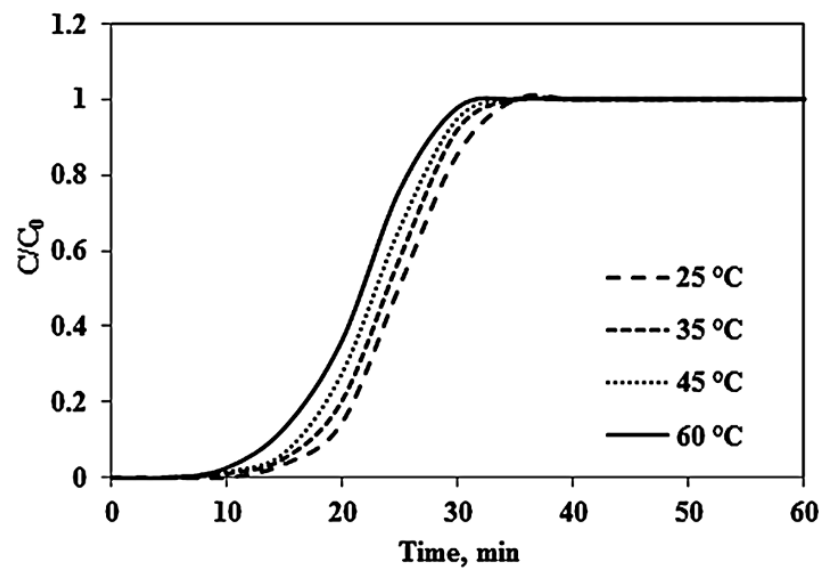

Fig. $4 \mathrm{CO}_{2}$ breakthrough curve for $\mathrm{AC}$ at $1 \mathrm{bar}$

\section{Adsorption isotherms}

In this study, the $\mathrm{CO}_{2}$ adsorption for each adsorbent was measured under a series of isothermal conditions (i.e., 25,
35,45 and $60{ }^{\circ} \mathrm{C}$ ). It can be seen that all isotherm curves exhibit common behavior regardless of temperature and adsorbent type which mean the amount of $\mathrm{CO}_{2}$ adsorbed on the adsorbent increases very rapidly with the increase in pressure over the low pressure range, and it tends to stabilize as the pressure continues to increase as shown in Figs. 5, 6 and 7. The isotherms behavior follows the type-I isotherm category according to IUPAC adsorption isotherm classification [26], which indicates a monolayer adsorption mechanism, commonly applied to micro-porous adsorbents.

The adsorption isotherms curves reveal the typical behavior showing the effect of temperature on the $\mathrm{CO}_{2}$ adsorption capacity. That is, an increase in adsorption temperature leads to a reduction in the amount of adsorbed $\mathrm{CO}_{2}$. Rising temperature simply provides more internal energy to $\mathrm{CO}_{2}$ molecules in the gas phase. It should be noted that the increasing energy allows gaseous molecules to diffuse at a greater rate, but, at the same time, it reduces the chance for the $\mathrm{CO}_{2}$ to be restrained or trapped by fixed energy adsorption sites on the adsorbent surface.

The amount of $\mathrm{CO}_{2}$ adsorbed by using zeolite $13 \mathrm{X}$ is 4.215 $\operatorname{mol}_{\mathrm{CO}_{2}} \mathrm{~kg}_{\text {sorbent }}^{-1}$ while the amount of $\mathrm{CO}_{2}$ adsorbed by using zeolite $4 \mathrm{~A}$ is $3.263 \mathrm{~mol}_{\mathrm{CO}_{2}} \mathrm{~kg}_{\text {sorbent }}^{-1}$ at 1 bar and a temperature of $25{ }^{\circ} \mathrm{C}$. AC gives the lowest adsorption capacity with an amount of $2.828 \mathrm{~mol}_{\mathrm{CO}_{2}} \mathrm{~kg}_{\text {sorbent }}^{-1}$ for this particular study. At higher temperature, $\mathrm{CO}_{2}$ adsorption capacity for the adsorbents decreases by 20-30\%. In addition, the slope of adsorption isotherm curve reveals the strength of interaction between $\mathrm{CO}_{2}$ molecules and the adsorption sites for individual sorbents. It appears that zeolite based adsorbents which exhibit greater slope of the adsorption curves have stronger adsorption sites as compare to AC. The experimental data were fitted to standard isotherm models like Langmuir and Freundlich model. The Langmuir isotherm equation can be represented as shown in Eq. 1 [27]

$q=\frac{q_{\mathrm{m}} K P_{\mathrm{CO}_{2}}}{1+K P_{\mathrm{CO}_{2}}}$

where $q$ is the amount of $\mathrm{CO}_{2}$ adsorbed at the $\mathrm{CO}_{2}$ partial pressure $P$ and $q_{\mathrm{m}}$ is the amount of $\mathrm{CO}_{2}$ adsorbed with monolayer coverage. The values of $q_{\mathrm{m}}$ and Langmuir constant $K$, calculated from the $\mathrm{CO}_{2}$ adsorption isotherms, are listed in Table 4. The monolayer $\mathrm{CO}_{2}$ coverage at the different temperatures $25,35,45$ and $60{ }^{\circ} \mathrm{C}$ were wellfitted for the zeolite adsorbents. While, Freundlich equation takes the form as shown in Eq. 2 [27]:

$q=K P_{\mathrm{CO}_{2}}^{1 / n}$

where $K$ and $n$ are Freundlich model constants. The $K$ and $n$ values of zeolite are higher than that of activated carbon. The Freunlich constant and regression co-efficient are given in Table 5 and agree well with AC. 


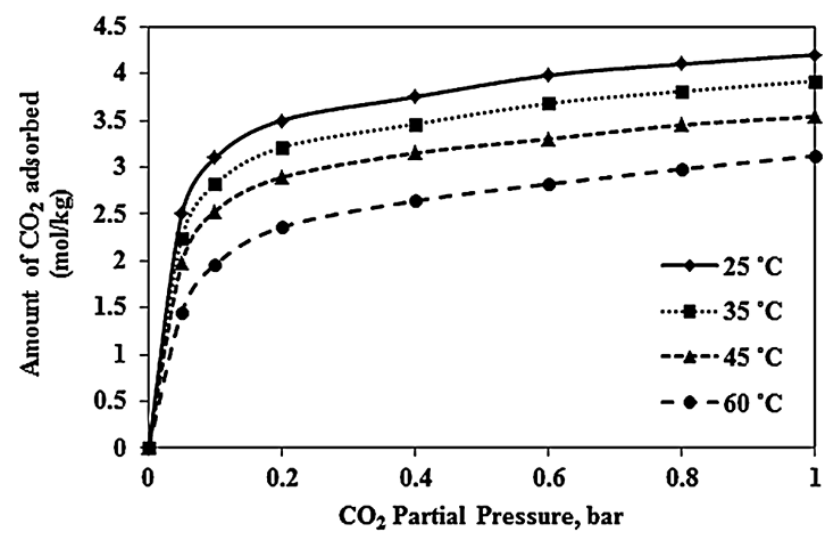

Fig. $5 \mathrm{CO}_{2}$ adsorption isotherms on zeolite $13 \mathrm{X}$

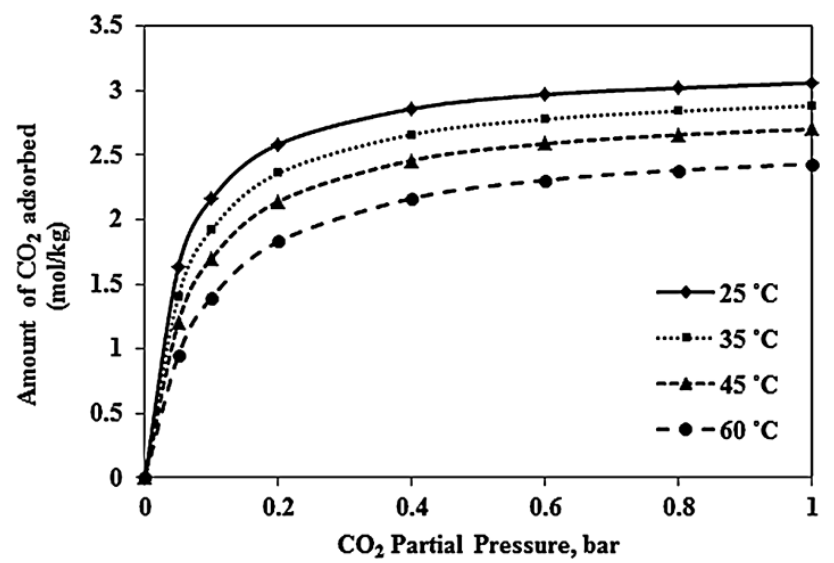

Fig. $6 \mathrm{CO}_{2}$ adsorption isotherms on zeolite $4 \mathrm{~A}$

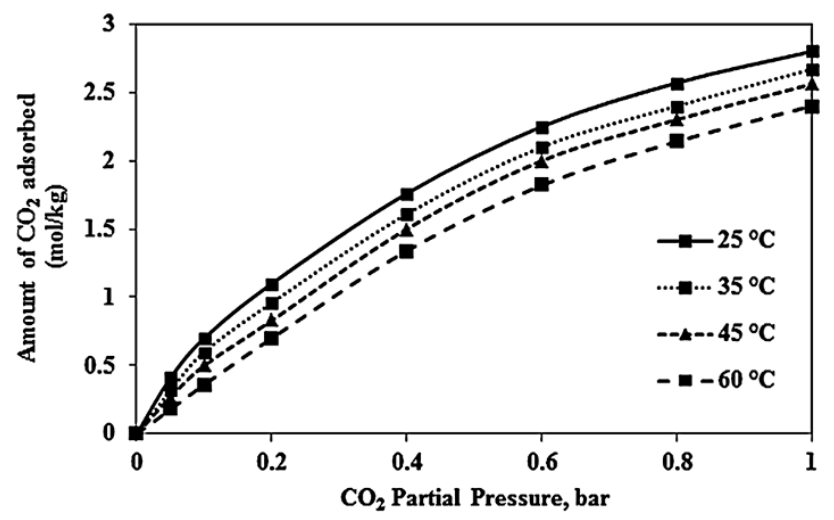

Fig. $7 \mathrm{CO}_{2}$ adsorption isotherm on $\mathrm{AC}$

The average percent deviation quantity, $\Delta q$, or the adsorbed amounts were calculated using the following formula given in Eq. 3 [28]:
Table 4 Langmuir constants and their regression coefficient

\begin{tabular}{|c|c|c|c|c|c|}
\hline \multirow[t]{2}{*}{ Material } & \multirow[t]{2}{*}{ Temp $\left({ }^{\circ} \mathrm{C}\right)$} & \multicolumn{2}{|c|}{ Langmuir constant } & \multirow[t]{2}{*}{$R^{2}$} & \multirow[t]{2}{*}{$\Delta \mathrm{q} \%$} \\
\hline & & $q_{\mathrm{m}}$ & $K$ & & \\
\hline \multirow[t]{4}{*}{ Zeolite $13 \mathrm{X}$} & 25 & 4.245 & 19.031 & 0.987 & 6.6 \\
\hline & 35 & 3.971 & 16.875 & 0.978 & 9.7 \\
\hline & 45 & 3.521 & 13.747 & 0.987 & 8.5 \\
\hline & 60 & 3.173 & 11.202 & 0.978 & 10.8 \\
\hline \multirow[t]{4}{*}{ Zeolite 4A } & 25 & 3.263 & 19.031 & 0.997 & 5.4 \\
\hline & 35 & 3.071 & 16.875 & 0.974 & 12.5 \\
\hline & 45 & 2.921 & 13.747 & 0.979 & 7.9 \\
\hline & 60 & 2.617 & 11.202 & 0.989 & 9.5 \\
\hline \multirow[t]{4}{*}{$\mathrm{AC}$} & 25 & 2.828 & 21.956 & 0.961 & 9.8 \\
\hline & 35 & 2.711 & 19.119 & 0.933 & 8.5 \\
\hline & 45 & 2.591 & 15.502 & 0.948 & 12.7 \\
\hline & 60 & 2.494 & 11.759 & 0.939 & 10.5 \\
\hline
\end{tabular}

Table 5 Freunlich constants and their regression coefficients

\begin{tabular}{lllllr}
\hline Material & Temp $\left({ }^{\circ} \mathrm{C}\right)$ & \multicolumn{2}{l}{ Freunlich constant } & $\mathrm{R}^{2}$ & \multirow{2}{*}{$\Delta \mathrm{q} \%$} \\
\cline { 3 - 4 } & & $K$ & & \\
\hline Zeolite 13X & 25 & 1.122 & 6.127 & 0.918 & 6.7 \\
& 35 & 1.034 & 5.483 & 0.938 & 10.5 \\
& 45 & 0.952 & 4.594 & 0.925 & 9.5 \\
& 60 & 0.836 & 3.812 & 0.973 & 12.3 \\
Zeolite 4A & 25 & 1.122 & 5.025 & 0.917 & 9.5 \\
& 35 & 1.034 & 4.386 & 0.923 & 11.2 \\
& 45 & 0.952 & 3.891 & 0.929 & 10.4 \\
& 60 & 0.836 & 3.311 & 0.937 & 9.7 \\
AC & 25 & 0.505 & 1.701 & 0.987 & 5.4 \\
& 35 & 0.447 & 1.551 & 0.982 & 8.4 \\
& 45 & 0.383 & 1.387 & 0.995 & 9.1 \\
& 60 & 0.346 & 1.319 & 0.986 & 6.7 \\
\hline
\end{tabular}

$\Delta q \%=\frac{100}{h} \sum_{j=1}^{h}\left|\frac{N^{\exp }-N^{\mathrm{cal}}}{N^{\exp }}\right|$

where $h$ is the number of experimental data and $N^{e x p}$ and $N^{c a l}$ are the experimental and calculated number of moles that are adsorbed by the adsorbent pellet.

Adsorption thermodynamics

The thermodynamic parameters are calculated from the Langmuir isotherms by using the Vant'Hoff's equation as follows in Eq. 4-6 [29]:

$\Delta G^{\circ}=-R T \ln K_{l}$ 
Table 6 Thermodynamic parameters for the adsorption of $\mathrm{CO}_{2}$

\begin{tabular}{cllll}
\hline Material & $\begin{array}{l}\text { Temp } \\
\left({ }^{\circ} \mathrm{C}\right)\end{array}$ & $\begin{array}{l}\Delta G^{\circ}(\mathrm{kJ} / \\
\mathrm{mol})\end{array}$ & $\begin{array}{l}\Delta H^{\circ}(\mathrm{kJ} / \\
\mathrm{mol})\end{array}$ & $\begin{array}{l}\Delta S^{\circ}(\mathrm{J} / \\
\mathrm{mol} . \mathrm{K})\end{array}$ \\
\hline Zeolite & 25 & -7.929 & -11.274 & 17.568 \\
13X & 35 & -7.689 & & \\
& 45 & -6.299 & & \\
& 60 & -6.236 & & \\
Zeolite $4 \mathrm{~A}$ & 25 & -7.299 & -12.852 & 18.499 \\
& 35 & -7.236 & & \\
& 45 & -6.929 & & \\
& 60 & -6.689 & & \\
AC & 25 & -7.653 & -14.98 & \\
& 35 & -7.556 & & \\
& 45 & -7.247 & & \\
& 60 & -6.824 & & \\
\hline
\end{tabular}

$\Delta H^{\circ}=R \frac{T_{1} T_{2}}{T_{2}-T_{1}} \ln \frac{K_{2}}{K_{1}}$

$\Delta S^{\circ}=\frac{\Delta H^{\circ}-\Delta G^{\circ}}{T}$

where $\Delta \mathrm{G}^{\circ}$ is change in the Gibb's free energy, $\Delta \mathrm{H}^{\circ}$ is change in the enthalpy and $\Delta \mathrm{S}^{\circ}$ is change in the entropy. A plot of $\ln K_{\text {eq }}$ vs. $1 / T$ should be a straight line with a slope $=-\Delta \mathrm{H}^{\mathrm{o}} / R$ and an intercept $=\Delta \mathrm{S}^{\mathrm{o}} / R$ which is called Van't Hoff equation.

The thermodynamic parameters, Gibbs free energy change, $\Delta G^{\circ}$ was calculated using Langmuir constants and the results are listed in Table 6 . The enthalpy change, $\Delta H^{\circ}$ and the entropy change, $\Delta S^{\circ}$, for the $\mathrm{CO}_{2}$ adsorption process on zoelite $13 \mathrm{X}$ are $-11.274 \mathrm{~kJ} / \mathrm{mol}$ and $17.568 \mathrm{~J} /$ $\mathrm{mol} \cdot K$ respectively, while the enthalpy change and entropy change for zeolite $13 \mathrm{X}$ and zeolite $4 \mathrm{~A}$ were calculated to give $-12.852 \mathrm{~kJ} / \mathrm{mol}$ and $-18.499 \mathrm{~J} / \mathrm{mol} \cdot K$ respectively. For AC, enthalpy change, $\Delta H^{\circ}$ and entropy change, $\Delta S^{\circ}$ are $-14.98 \mathrm{~kJ} / \mathrm{mol}$ and $-24.379 \mathrm{~J} / \mathrm{mol} . \mathrm{K}$ respectively. The negatives values of $\Delta G^{\circ}$ confirm the feasibility of the process and the spontaneous nature of the adsorption process. The negative values in $\Delta H^{\circ}$ indicated that the adsorption reaction is exothermic for all the adsorbents used. The positive value of $\Delta S^{\circ}$ reflects the affinity of the adsorbents with $\mathrm{CO}_{2}$ and suggests some structural change in $\mathrm{CO}_{2}$ and the adsorbents.

\section{Regeneration study}

The three adsorbents were tested for material aging by using the same adsorbent over five adsorption desorption cycles at $25{ }^{\circ} \mathrm{C}$ and at 1 bar. The desorption process is achieved by increasing the bed temperature up to $100{ }^{\circ} \mathrm{C}$ which increases the internal energy of the gas and allowed the gas molecules to escape from the reactor. Figure 8

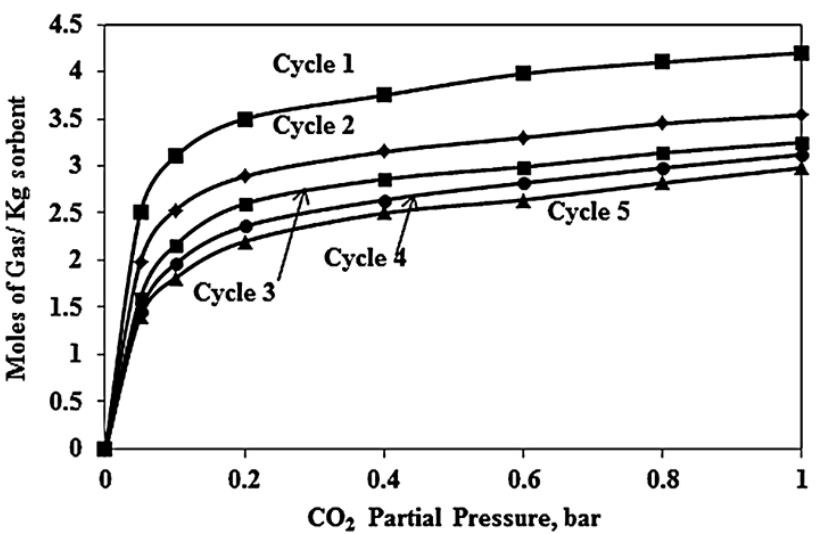

Fig. 8 Adsorption isotherms of zeolite $13 \mathrm{X}$

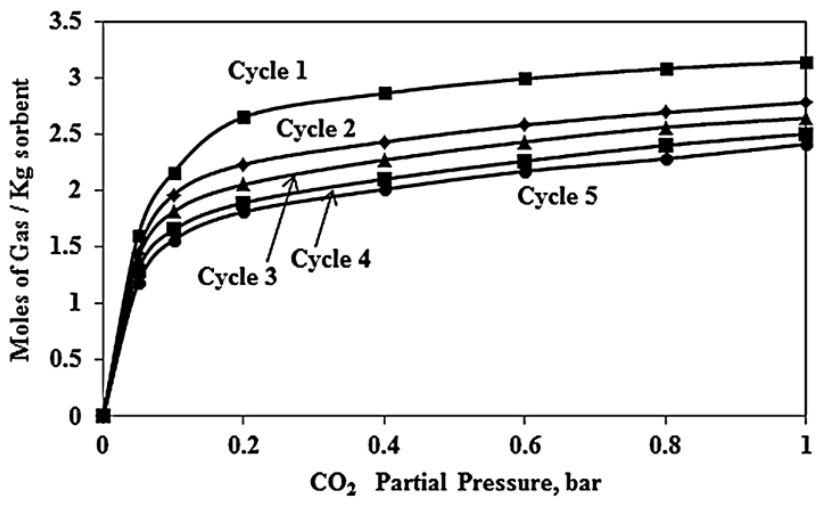

Fig. 9 Adsorption isotherms of zeolite 4A

shows the adsorption isotherms of $\mathrm{CO}_{2}$ zeolite $13 \mathrm{X}$ at $25{ }^{\circ} \mathrm{C}$ for five cycles. Up to 0.2 bar the $\mathrm{CO}_{2}$ adsorption increased rapidly when the pressure was increased. The increase in $\mathrm{CO}_{2}$ adsorption after 0.2 bar appeared to be gradual. The adsorption isotherms for repeated cycles showed a reduction in the amount of adsorption for the next cycles. This indicated that the adsorption is not reversible and complete regeneration cannot be obtained by adsorption of the material after adsorption. The amount of adsorption is almost similar for cycles 4 and 5 which indicate that the adsorbent is almost saturated with $\mathrm{CO}_{2}$ (Table 6).

The adsorption isotherms for zeolite $4 \mathrm{~A}$ are shown in Fig. 9 and shows that the adsorption isotherms of $\mathrm{CO}_{2}$ for zeolite $4 \mathrm{~A}$ is not highly reproducible, indicating that the adsorption is not completely reversible. The adsorption at the first cycle was the highest. The uptake of $\mathrm{CO}_{2}$ for molecular sieve 4A was lower than that of molecular sieve $13 \mathrm{X}$ at all pressures up to 1 bar. The adsorption isotherms for $\mathrm{AC}$ are shown in Fig. 10. It is interesting to note that all the isotherms are extremely reproducible, which indicates the excellent reversibility of adsorption. The $\mathrm{CO}_{2}$ uptake for $\mathrm{AC}$ was lower than that of the two 


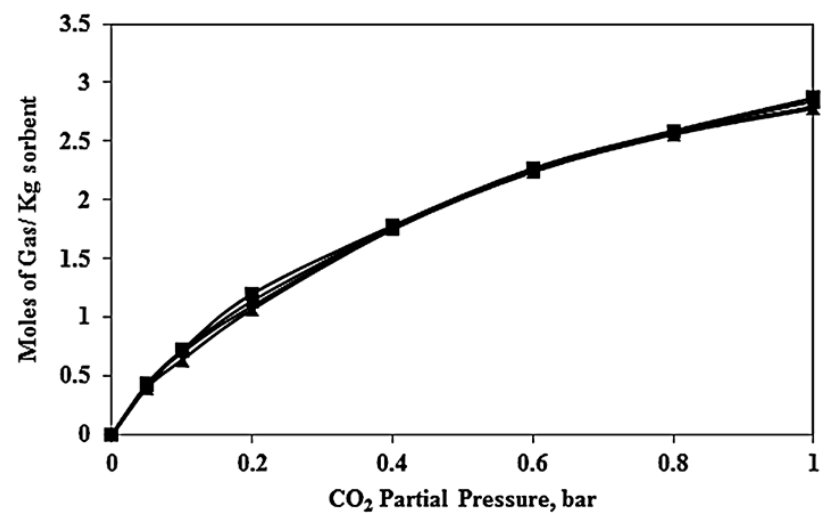

Fig. 10 Adsorption isotherms of AC

zeolite at lower pressures, but at higher pressures (up to 35 bar) the $\mathrm{CO}_{2}$ uptake for $\mathrm{AC}$ was higher than that of the zeolites [25].

\section{Conclusions}

The $\mathrm{CO}_{2}$ adsorption experiments were conducted using gravimetric method at different temperatures and pressures. From this study, it was concluded that the $\mathrm{CO}_{2}$ adsorption isotherm obtained in this study followed general gas adsorption behavior, demonstrating that the $\mathrm{CO}_{2}$ adsorption capacity increases with increasing pressure and decreases with increasing temperature. The adsorption isotherm follows a type-I isotherm classification according to IUPAC, representing a monolayer adsorption mechanism. Among the three adsorbents tested, zeolite $13 \mathrm{X}$ offers the highest adsorption capacity, and AC provides the lowest capacity at temperatures ranging from 25 to $60{ }^{\circ} \mathrm{C}$ and pressures up to 1 bar. The experimental data of $\mathrm{CO}_{2}$ adsorption were fitted with Langmuir and Freunlich isotherm models. It was found that Langmuir model showed the best fit with the zeolite $13 \mathrm{X}$ and zeolite $4 \mathrm{~A}$ while Freunlich model provided excellent fit with AC. The thermodynamics parameter were calculated from Van't Hoff's equation and concluded that the adsorption experiment were exothermic in nature for the three adsorbents. There is no full regeneration for zoelites while a full regeneration can be achieved with AC.

Authors' contributions All authors have been involved in drafting the manuscript and approved the final manuscript.

Acknowledgments This study has been funded by the Indian Institute of Technology Guwahati.

Conflict of interest The authors declare that there are no conflicts of interests regarding the publication of this article.
Open Access This article is distributed under the terms of the Creative Commons Attribution License which permits any use, distribution, and reproduction in any medium, provided the original author(s) and the source are credited.

\section{References}

1. Song, C.: Global challenges and strategies for control, conversion and utilization of $\mathrm{CO}_{2}$ for sustainable development involving energy, catalysis, adsorption and chemical processing. Catal Today 115, 2-32 (2006)

2. Metz, B., Davidson, O., Coninck, H., de, Loos, M., Meyer, L.: Carbon dioxide capture and storage, International Panel on Climate Control. Cambridge University Press, IPCC) (2005)

3. Yang, H., Xu, Z., Fan, M., Gupta, R., Slimane, R.B., Bland, A.E., Wright, I.: Progress in carbon dioxide separation and capture: A review. J Environ Sci 20, 14-27 (2008)

4. Self, et al.: Review of underground coal gasification technologies and carbon capture. Int J Energ Environ Eng 3, 16 (2012)

5. Konduru, N., Linder, P., Assaf-Anid, N.M.: Curbing the greenhouse effect by carbon dioxide adsorption with zeolite $13 \mathrm{X}$. Wiley Inter Sci 53(12), 3137-3143 (2007)

6. Kuramochi, T., Faaij, A., Ramırez, A., Turkenburg, W.: Prospects for cost-effective post-combustion $\mathrm{CO}_{2}$ capture from industrial CHPs. Int. J. Greenh. Gas. Control. 4, 511-524 (2010)

7. Hurtado, A., Eguilior, S., Recreo, F.: Methodological development of a probabilistic model for $\mathrm{CO}_{2}$ geological storage safety assessment. Int. J. Energy. Environ. Eng. 5, 84 (2014)

8. Agarwal, A., Biegler, L.T., Zitney, S.E.: A super structure-based optimal synthesis of PSA cycles for post-combustion $\mathrm{CO}_{2}$ capture. AIChE J 56, 1813-1828 (2010)

9. Chue, K.T., Kim, J.N., Yoo, Y.J., Cho, S.H., Yang, R.T.: Comparison of activated carbon and zeolite $13 \mathrm{X}$ for $\mathrm{CO}_{2}$ recovery from flue gas by pressure swing adsorption. Ind. Eng. Chem. Res. 34, 591-598 (1995)

10. Sircar, S., Kratz, W.C.: Simultaneous production of hydrogen and carbon dioxide from steam reformer off-gas by pressure swing adsorption. Sep. Sci. Technol. 23, 2397-2415 (1988)

11. Xu, X., Song, C., Miller, B.G., Scaroni, A.W.: Adsorption separation of carbon dioxide from flue gas of natural gas-fired boiler by a novel nanoporous "molecular basket" adsorbent. Fuel. Process. Technol. 86, 1457-1472 (2005)

12. Drage, T.C., Arenillas, A., Smith, K.M., Pevida, C., Piippo, S., Snape, C.E.: Preparation of carbon dioxide adsorbents from the chemical activation of urea-formaldehyde and melamine-formaldehyde resins. Fuel 86, 22-31 (2007)

13. Ribeiro, R.P.P.L., Grande, C.A., Rodrigues, A.E.: Activated carbon honeycomb monolith-Zeolite13X hybrid system to capture $\mathrm{CO}_{2}$ from flue gases employing Electric Swing Adsorption. Chem. Eng. Sci. 104, 304-318 (2013)

14. Cheung, O., Bacsik, Z., Liu, Q., Mace, A., Hedin, N.: Adsorption kinetics for $\mathrm{CO}_{2}$ on highly selective zeolites NaKA and nanoNaKA. Appl. Energy 112, 1326-1336 (2013)

15. Thang, H.V., Grajciar, L., Nachtigall, P., Bludsḱy, O., Areán, C.O., Fŕydová, E., Bulánek, R.: Adsorption of $\mathrm{CO}_{2}$ in FAU zeolites: Effect of zeolite composition. Catal. Today. 227, 50-56 (2014)

16. Chen, C., Park, D.W., Ahn, W.S.: $\mathrm{CO}_{2}$ capture using zeolite $13 \mathrm{X}$ prepared from bentonite. Appl. Surf. Sci. 292, 63-67 (2014)

17. He, X., Lie, J.A., Sheridan, E., Hägg, M.B.: $\mathrm{CO}_{2}$ Capture by Hollow Fibre Carbon Membranes: Experiments and Process Simulations. Energy Proced. 1, 261-268 (2009)

18. Skarstrom: C. W. U.S. Patent 2, 944, 627 (1960) 
19. Tlili, N., Grevillot, G., Vallieres, C.: Carbon dioxide capture and recovery by means of TSA and/or VSA. Int. J. Greenh. Gas Control 3, 519-527 (2009)

20. Guerrin de M., Domine P.: D. U.S. Patent 3,155, 468 (1964)

21. Ruthven, D., Farooq, S., Knaebel, K.S.: Pressure swing adsorption, p. 352. VCH, New York (1994)

22. Adeyemo, A., Kumar, R., Linga, P., Ripmeester, J., Englezos, P.: Capture of carbon dioxide from flue or fuel gas mixtures by clathrate crystallization in a silica gel column. Int. J. Greenh. Gas Control 4, 478-485 (2010)

23. Pugsley, T.S., Berruti, F., Chakma, A.: Computer simulation of a novel circulating fluidized bed pressure- temperature swing adsorber for recovering carbon dioxide from flue gasses. Chem. Eng. Sci. 49(24A), 4465-4481 (1994)

24. Chue K., Jong-Nam K., Yun-Jong Y., Soon-Haeng C., in Fundamentals of Adsorption, ed. by LeVan, D., Kluwer Proc. Int. Conf., (Academic Publishers: Boston, MA, 1996) p. 203-210
25. Pellerano, M., Pre, P., Kacem, M., Delebarre, A.: $\mathrm{CO}_{2}$ capture by adsorption on activated carbon by pressure modulation. Energy Procedia 1, 647-653 (2009)

26. Keller, J.U., Staudt, R.: Gas adsorption equilibria: experimental methods and adsorptive isotherms. Springer Science and Business Media Inc, Boston (2005)

27. Guo, B., Chang, L., Xie, K.: Adsorption of carbon dioxide on activated carbon. J. Nat. Gas Chem. 15, 223-229 (2006)

28. Morse, G., Jones, R., Thibault, J., Tezel, F.H.: Neural network modeling of adsorption isotherms. Adsorption 17(2), 303-309 (2010)

29. Alzaydien, A.S., Manasreh, W.: Equilibrium, kinetics and thermodynamic studies on the adsorption of phenol onto activated phosphate rock. Int. J. Phy. Sci. 4(4), 172-181 (2009) 